\title{
Plasma leptin and ghrelin in the neonatal rat: interaction of dexamethasone and hypoxia
}

\author{
Eric D Bruder ${ }^{1}$, Lauren Jacobson ${ }^{2}$ and Hershel Raff ${ }^{1,3}$ \\ ${ }^{1}$ Endocrine Research Laboratory, St Luke's Medical Center, Milwaukee, Wisconsin 53215, USA \\ ${ }^{2}$ Center for Neuropharmacology and Neurosciences, Albany Medical College, Albany, New York 12208, USA \\ ${ }^{3}$ Department of Medicine, Medical College of Wisconsin, Milwaukee, Wisconsin 53226, USA \\ (Requests for offprints should be addressed to H Raff, Endocrinology, St Luke's Physician's Office Building, 2801 W. KK River Pky, Suite 245, Milwaukee, \\ Wisconsin 53215, USA; Email: hraff@mcw.edu)
}

\begin{abstract}
Ghrelin, leptin, and endogenous glucocorticoids play a role in appetite regulation, energy balance, and growth. The present study assessed the effects of dexamethasone (DEX) on these hormones, and on ACTH and pituitary proopiomelanocortin (POMC) and corticotropin-releasing hormone receptor-1 (CRHR1) mRNA expression, during a common metabolic stress - neonatal hypoxia. Newborn rats were raised in room air $\left(21 \% \mathrm{O}_{2}\right)$ or under normobaric hypoxia $\left(12 \% \mathrm{O}_{2}\right)$ from birth to postnatal day (PD) 7. DEX was administered on PD3 (0.5 mg/kg), PD4 $(0.25 \mathrm{mg} / \mathrm{kg})$, PD5 $(0.125 \mathrm{mg} / \mathrm{kg})$, and PD6 (0.05 mg/ $\mathrm{kg}$ ). Pups were studied on PD7 (24 h after the last dose of DEX). DEX significantly increased plasma leptin and ghrelin in normoxic pups, but only increased ghrelin in hypoxic pups. Hypoxia alone resulted in a small increase in
\end{abstract}

plasma leptin. Plasma corticosterone and pituitary POMC mRNA expression were decreased $24 \mathrm{~h}$ following the last dose of DEX, whereas plasma ACTH and pituitary CRHR1 mRNA expression had already increased (normoxia and hypoxia). Hypoxia alone increased corticosterone, but had no effect on ACTH or pituitary POMC and CRHR1 mRNA expression. Neonatal DEX treatment, hypoxia, and the combination of both affect hormones involved in energy homeostasis. Pituitary function in the neonate was quickly restored following DEX-induced suppression of the hypothalamic-pituitary-adrenal axis. The changes in ghrelin, leptin, and corticosterone may be beneficial to the hypoxic neonate through the maintenance of appetite and shifts in intermediary metabolism.

Journal of Endocrinology (2005) 185, 477-484

\section{Introduction}

An integrated endocrine response is a critical component of the physiological adaptation to metabolic disturbances in the neonate (Grongnet 1984, Frankel \& Stevenson 1987, Friedman \& Fahey 1993, Zayour et al. 2003). Critical hormones in the control of metabolism and appetite are leptin, produced by adipocytes (Neary et al. 2004), ghrelin, produced primarily by the stomach (Small \& Bloom 2004), and adrenal corticosteroids (Dallman 2003). These hormones have complex interactions ultimately controlling food intake, growth, development, and energy balance in the neonate and adult (Meier \& Gressner 2004). Of particular interest is the role that these hormones play in the neonatal adaptation to stress and disease (Zayour et al. 2003).

Neonatal bronchopulmonary dysplasia leads to hypoxia, and can occur in up to $23 \%$ preterm human births in the USA (American Academy of Pediatrics \& Canadian Paediatric Society 2002). Glucocorticoid therapy is sometimes required in the treatment of neonatal respiratory distress and acts primarily to promote lung maturation (Sinkin et al. 2000). However, glucocorticoid therapy is associated with both short- and long-term negative consequences (Raff 2004, Yeh et al. 2004). We have examined many facets of the endocrine and metabolic adaptation to neonatal hypoxia (Raff et al. 1999a,b, 2001a, Raff 2003) and its interaction with dexamethasone therapy (Bruder et al. 2004, 2005). Of relevance to the current study is the dramatic decrease in growth that occurs, without a change in body composition, during hypoxia (Raff et al. 2001b). Glucocorticoid therapy also decreases growth rate (He et al. 2004), and interacts with hypoxia to lead to an almost complete cessation in neonatal growth (Bruder et al. 2004). Finally, both hypoxia and glucocorticoid therapy lead to dramatic disturbances in lipid metabolism and gastrointestinal function (Lee et al. 2002, 2003, Bruder et al. 2004, 2005).

The goal of the present study was to further evaluate the metabolic and developmental effects of neonatal hypoxia and its interaction with dexamethasone treatment. Hypoxia and dexamethasone may independently alter food 
intake and metabolism (Kayser 1992, Raff et al. 1999a, 2001a, Raff 2003, Bruder et al. 2004). We hypothesized that hypoxia may attenuate dexamethasone-induced increases in leptin (Spinedi \& Gaillard 1998), perhaps to encourage an increase in food intake. We also wanted to explore the effect of dexamethasone and hypoxia on ghrelin, another hormonal controller of appetite and metabolism in the neonate (Soriano-Guillen et al. 2004). Since leptin, ghrelin, and adrenal corticosteroids have reciprocal effects on one another (Spinedi \& Gaillard 1998, Ishida-Takahashi et al. 2004, Meier \& Gressner 2004, Soriano-Guillen et al. 2004), we assessed components of the hypothalamic-pituitary-adrenal (HPA) axis to determine if changes in leptin or ghrelin might be ascribed to altered HPA activity.

\section{Materials and Methods}

\section{Animal treatment}

All experimentation was approved by the Institutional Animal Care and Use Committees of the Medical College of Wisconsin and St Luke's/Aurora Sinai Medical Center. Timed pregnant Sprague-Dawley rats (Harlan SpragueDawley, Inc., Indianapolis, IN, USA; $n=16)$ were obtained at 14 days of gestation and maintained on a standard sodium diet (Richmond Standard 5001, Brentwood, MO, USA) and water ad libitum in a controlled environment (lights on from 0600 to $1800 \mathrm{~h}$ ). Parturition usually occurred on the afternoon of gestational day 22, during which time the rats were kept under observation. After litters were completely delivered, transferring no more than one to two pups from one dam to another equalized litter size. This is a standard technique to minimize the metabolic and hormonal effects of differences in numbers of pups in each litter (Routh et al. 1993, Young 2002). The dam and pups ( $\sim 13$ per litter) were then exposed to normobaric hypoxia $\left(12 \% \mathrm{O}_{2}\right)$ or kept in room air as controls $\left(21 \% \mathrm{O}_{2}\right)$ as described previously (Raff \& Chadwick 1986, Raff et al. 1999b). We have previously shown that this exposure leads to arterial plasma $\mathrm{O}_{2}$ levels in adults of about 50-55 torr with sustained hypocapnia and alkalosis (Raff \& Chadwick 1986, Raff et al. 1986).

Lactating dams were maintained with their litters for 7 days in a hypoxic or normoxic environment (Thomas \& Marshall 1995). Dexamethasone phosphate (Sigma Chemical Co., St Louis, MO, USA) was administered subcutaneously in a tapering regimen to normoxic and hypoxic pups at $0800 \mathrm{~h}$ as follows: post-natal day (PD) 3 $(0.5 \mathrm{mg} / \mathrm{kg})$, PD4 $(0.25 \mathrm{mg} / \mathrm{kg})$, PD5 $(0.125 \mathrm{mg} / \mathrm{kg})$, and PD6 $(0.05 \mathrm{mg} / \mathrm{kg}$ ) (Flagel et al. 2002). This tapering pattern of dexamethasone administration was designed to mimic glucocorticoid therapy used in the clinical setting. Control pups were injected with saline. Pups were weighed on each day of injection. At $0800 \mathrm{~h}$ on PD7 (24 h after the last dexamethasone injection), dams were re- moved from the chambers. Pups were quickly decapitated and blood from each pup was pooled (three pups per sample) and immediately placed on ice. Plasma was separated and frozen for subsequent analysis $(n=4-10$ per treatment). Pituitaries were removed and processed as described below. Samples were obtained from pups from four normoxic and four hypoxic litters.

\section{Plasma measurements}

All measurements were performed on pooled samples from each treatment group (three pups/sample). Leptin was measured by enzyme-linked immunosorbent assay (Crystal Chem. Inc., Downers Grove, IL, USA) with an inter- and intra-assay coefficient of variation (C.V.) of 7\% and $5 \%$ respectively. Leptin measurements were verified in some samples by RIA (Linco Research, Inc., St Charles, MO, USA) with an inter- and intra-assay C.V. of $6 \%$ and $5 \%$ respectively. Ghrelin was measured by enzyme immunoassay (Phoenix Pharmaceuticals Inc., Belmont, CA, USA) with an inter- and intra-assay C.V. of $<14 \%$ and $<5 \%$ respectively. Corticotropin $(\mathrm{ACTH}$; inter- and intra-assay C.V. $=11 \%$ and $7 \%$ ) and corticosterone (interand intra-assay C.V. $=7 \%$ and $6 \%$ ) were measured by RIA (MP Biomedicals Inc., Orangeburg, NY, USA).

\section{Pro-opiomelanocortin (POMC) and corticotropin-releasing hormone receptor-1 (CRHR1) $m R N A$ expression}

Northern analysis of pituitary gene expression was performed using previously published techniques (Jacobson et al. 1997). Anterior pituitaries were dissected from the neurointermediate lobe at death and snap-frozen in liquid nitrogen (three pituitaries per tube). Total RNA was isolated using the TRI Reagent procedure (Molecular Research Center, Cincinnati, OH, USA), fractionated on $1.4 \%$ agarose gels containing $0.6 \mathrm{M}$ formaldehyde, transferred to nylon membranes in $20 \times$ SSC, and immobilized by u.v. cross-linking. Antisense ${ }^{32} \mathrm{P}-$ labeled cRNA probes were transcribed from appropriately linearized plasmids using T3 or T7 RNA polymerase (Stratagene, La Jolla, CA, USA) from cDNA clones complementary to mouse POMC (Jacobson 2000, Raff et al. 2003), rat CRHR1 (Pozzoli et al. 1996), or human 28S mRNA (Ambion, Austin, TX, USA). CRHR1 probes were produced from a $461 \mathrm{bp}$ cDNA clone based on a previously published sequence (Perrin et al. 1993), and generously provided by Neurocrine Biosciences (San Diego, CA, USA). Membranes were hybridized at $65{ }^{\circ} \mathrm{C}$ in $50 \%$ formamide, $2 \%$ SDS, and $0.8 \mathrm{M} \mathrm{NaCl}$, and washed three times in $0 \cdot 1 \times \operatorname{SSC}$ and $0 \cdot 1 \% \operatorname{SDS}\left(65^{\circ} \mathrm{C}\right)$. After washing, blots were exposed to phosphoimager screens (GE Healthcare, Sunnyvale, CA, USA). The resulting autoradiographic images were analyzed using Imagequant $5 \cdot 0$ software (GE Healthcare), with the CRHR 1 and POMC signals normalized to $28 \mathrm{~S}$ ribosomal RNA $(n=7-11)$. 


\section{Statistical analyses}

Results are reported as means \pm S.E.M. Data were analyzed by two-way ANOVA and the Student-Newman-Keuls method for multiple comparisons (SigmaStat 2·03).

\section{Results}

Average body weight at PD6 was $11 \cdot 4 \pm 0 \cdot 2 \mathrm{~g}(n=99)$ in normoxic controls. Average body weight of normoxic pups at PD6 treated with dexamethasone was 23\% lower than control $(8 \cdot 8 \pm 0 \cdot 2 \mathrm{~g} ; n=95 ; P<0 \cdot 05)$. Pups exposed to hypoxia had an average body weight that was $25 \%$ lower than normoxic controls at PD6 $(8 \cdot 6 \pm 0 \cdot 2 \mathrm{~g} ; n=104$; $P<0 \cdot 05)$. Pups exposed to hypoxia and treated with dexamethasone had an average body weight at PD6 that was $39 \%$ lower than normoxic controls $(7 \cdot 0 \pm 0 \cdot 1 \mathrm{~g}$; $n=112 ; P<0 \cdot 05)$. The combination of dexamethasone and hypoxia had an additive negative effect on body weight.

The effects of dexamethasone on plasma concentrations of leptin (Fig. 1 upper panel) and ghrelin (Fig. 1 lower panel) in 7-day-old pups are shown. Daily dexamethasone administration on days 3-6 in a tapering dose regimen increased plasma leptin nearly sevenfold in 7-day-old normoxic pups $(P<0 \cdot 001)$. There was a small but significant increase in plasma leptin concentration during hypoxia alone $(P<0 \cdot 02)$. Hypoxia attenuated the leptin response to dexamethasone, although it was still increased compared with normoxic, vehicle-treated controls $(P<0 \cdot 001)$. There was a significant increase in the plasma concentration of ghrelin in normoxic pups after dexamethasone treatment $(P<0 \cdot 001)$. Hypoxia alone had no effect on plasma ghrelin and did not modify the dexamethasone-induced increase in ghrelin $(P<0 \cdot 001)$.

Figure 2 depicts plasma ACTH (upper left panel), plasma corticosterone (upper right panel), and pituitary POMC and CRHR1 mRNA expression (lower panels). Prior dexamethasone treatment decreased subsequent plasma corticosterone concentration in 7-day-old normoxic pups to levels nearly half that of vehicle-treated normoxic controls $(P<0 \cdot 001)$. Plasma corticosterone concentration was nearly doubled in hypoxic pups $(P<0 \cdot 001)$, but this effect was blocked by prior dexamethasone $(P<0 \cdot 001)$. Prior dexamethasone treatment also resulted in a significant increase in plasma ACTH on day $7(24 \mathrm{~h}$ after the last dexamethasone injection) in normoxic $(P<0 \cdot 02)$ and hypoxic $(P=0 \cdot 007)$ pups. Hypoxia alone had no effect on plasma ACTH concentration. Prior treatment with dexamethasone decreased pituitary POMC mRNA expression, measured $24 \mathrm{~h}$ after the last dexamethasone injection, over twofold in normoxic $(P=0.002)$ and hypoxic $(P=0.009)$ pups. Hypoxia had no effect on pituitary POMC mRNA expression, and there were no differences in dexamethasone-induced decreases between normoxic and hypoxic pups $(P>0 \cdot 05)$. Prior treatment with dexamethasone increased pituitary CRHR $1 \mathrm{mRNA}$
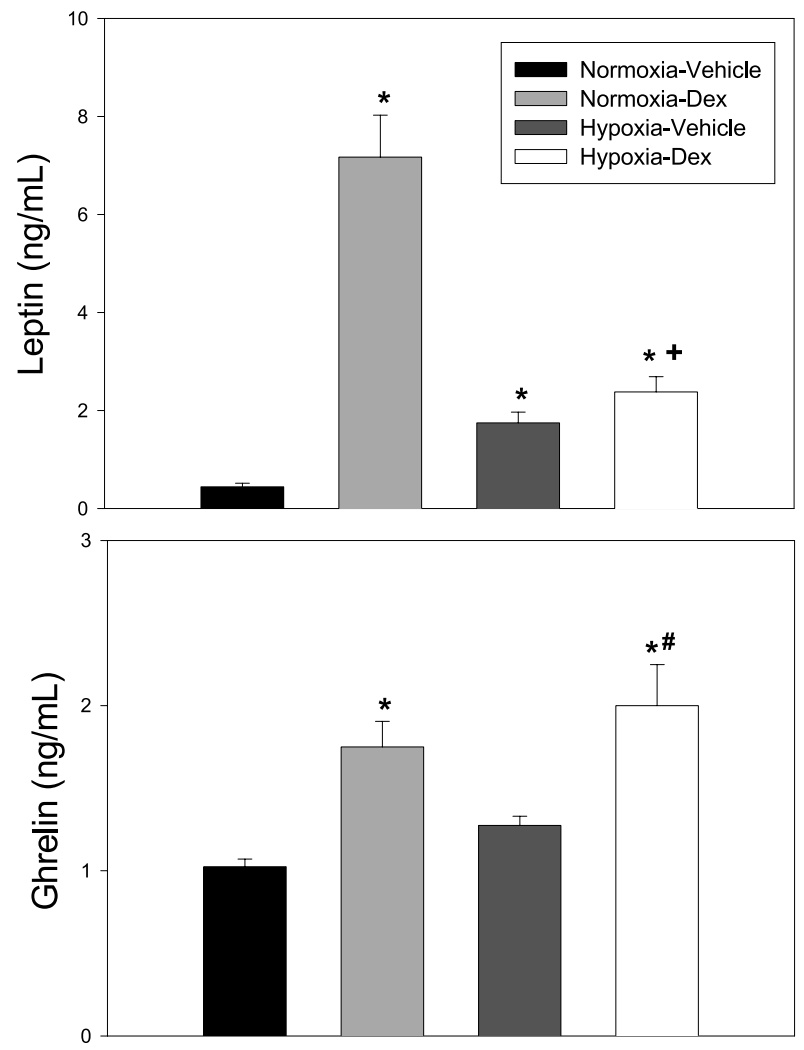

Figure 1 Effects of dexamethasone and/or hypoxia on plasma leptin and ghrelin concentrations in the neonatal rat. Rats were exposed to hypoxia from birth to 7 days of age and treated with a tapering dose regimen of dexamethasone (Dex) (or vehicle) from PD3 to PD6. Plasma from three pups was pooled to create one sample. *Indicates a significant difference from Normoxia-Vehicle with $P<0 \cdot 05 .{ }^{\#}$ Indicates a significant difference from Hypoxia-Vehicle with $P<0 \cdot 05 .{ }^{+}$Indicates a significant difference from Normoxia-Dex with $P<0 \cdot 05$. $n$ values for leptin measurements were: Normoxia-Vehicle (11), Normoxia-Dex (7), Hypoxia-Vehicle (9), and Hypoxia-Dex (7). n values for ghrelin measurements were: Normoxia-Vehicle (8), Normoxia-Dex (4), Hypoxia-Vehicle (8), and Hypoxia-Dex (4).

expression $(P=0 \cdot 013)$, regardless of inspired $\mathrm{O}_{2}$, when measured $24 \mathrm{~h}$ after the last dexamethasone injection (7 days of age).

\section{Discussion}

The present study examined the interaction of glucocorticoid therapy and a common neonatal metabolic stress (hypoxia) on plasma leptin and ghrelin concentrations in the 7-day-old rat pup. Dexamethasone treatment per se significantly increased plasma leptin and ghrelin concentrations. Concomitant hypoxia attenuated the leptin, but not ghrelin, response to dexamethasone. These findings, to the best of our knowledge, are the first to describe 

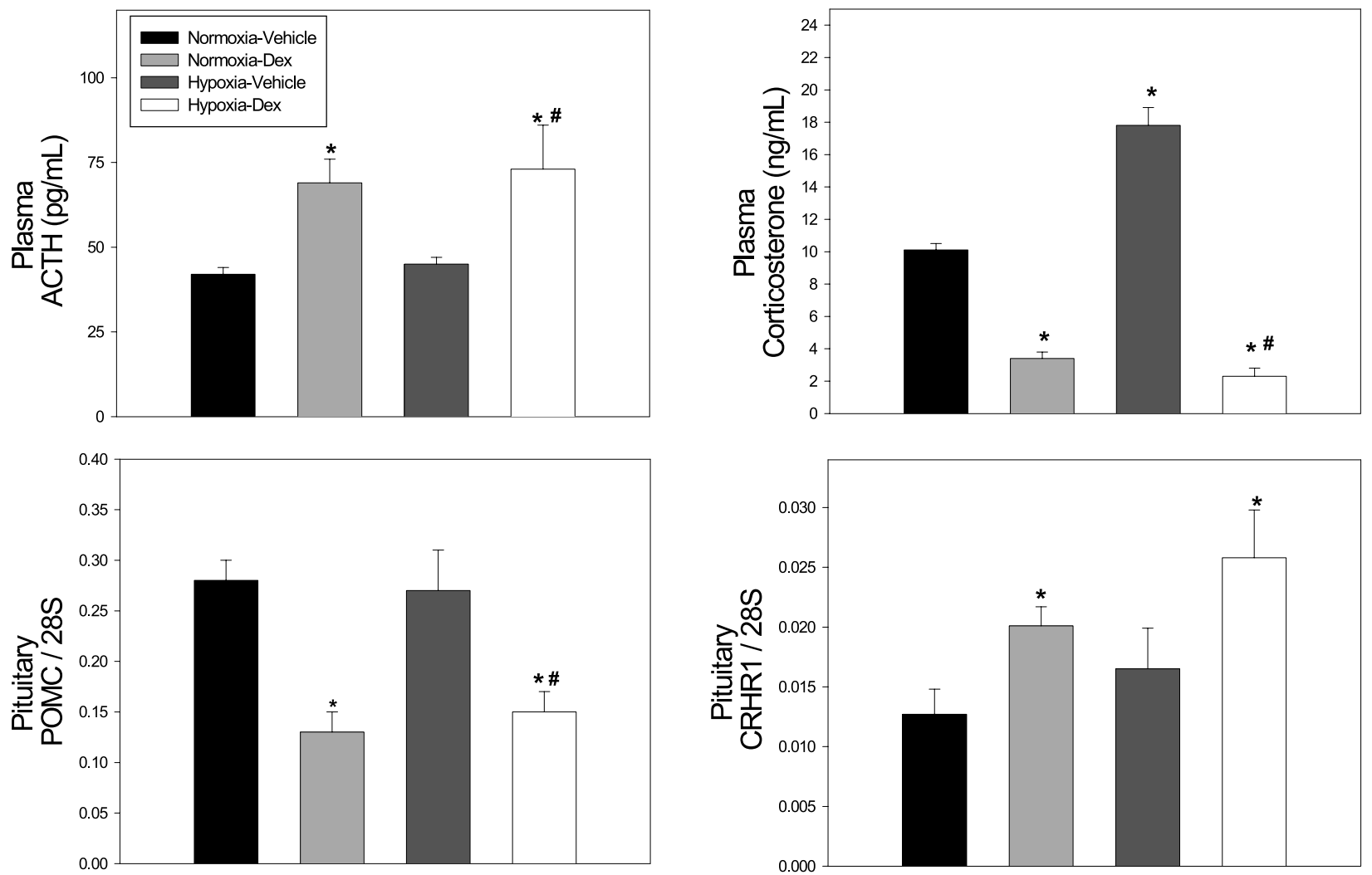

Figure 2 Effects of dexamethasone and/or hypoxia on plasma ACTH, plasma corticosterone, and pituitary POMC and CRHR1 mRNA expression in the neonatal rat. Rats were exposed to hypoxia from birth to 7 days of age and treated with a tapering dose regimen of dexamethasone (Dex) (or vehicle) from PD3 to PD6. Plasma from three pups was pooled to create one sample. Pituitary POMC and CRHR1 expression was measured using a Northern blot technique. ${ }^{*}$ Indicates a significant difference from Normoxia-Vehicle with $P<0.05$. "Indicates a significant difference from Hypoxia-Vehicle with $P<0 \cdot 05 . n$ values for plasma corticosterone and ACTH measurements were: Normoxia-Vehicle (10), Normoxia-Dex (6), Hypoxia-Vehicle (10), and Hypoxia-Dex (8). $n$ values for POMC measurements were: Normoxia-Vehicle (11), Normoxia-Dex (7), Hypoxia-Vehicle (9), and Hypoxia-Dex (7). $n$ values for pituitary CRHR1 measurements were: Normoxia-Vehicle (5), Normoxia-Dex (6), Hypoxia-Vehicle (6), and Hypoxia-Dex (6).

dexamethasone-associated increases in plasma ghrelin in the normoxic or hypoxic neonatal rat.

\section{Leptin}

Dexamethasone treatment in preterm infants has been shown to increase serum leptin and insulin concentrations ( $\mathrm{Ng}$ et al. 2002). We have previously observed significant hyperinsulinemia in rat pups treated with the same dexamethasone regimen as the current study (Bruder et al. 2004). It has been suggested that there is no direct effect of dexamethasone on leptin, but rather an indirect effect of the dexamethasone-induced inhibition of ACTH (Spinedi \& Gaillard 1998). We infer that ACTH was suppressed during dexamethasone therapy (PD3-6) since corticosterone levels were very low (see below for discussion of $\mathrm{ACTH}$. It is possible, therefore, that dexamethasoneinduced decreases in plasma ACTH may indirectly result in increased leptin. Dexamethasone may also increase the concentration of free leptin while having no effect on bound leptin or the soluble leptin receptor (Lewandowski et al. 2001). A recent study found that glucocorticoids antagonize leptin action through rapid inhibition of the signaling cascade associated with the leptin receptor (Ishida-Takahashi et al. 2004). The above findings confirm an intimate relationship between the HPA axis and adipocyte leptin production in the neonate.

We have previously shown that hypoxia from birth to 7 days of age in unhandled rat pups resulted in a small but significant decrease in plasma leptin at 7 days of age ( $R$ aff et al. 2001a). This previous study used a leptin RIA while the present study utilized an enzyme-immunoassay. In order to verify the present results, we re-assayed some samples using the older RIA method and the two assay methods were in agreement. Increased plasma leptin in the present study may be attributed to the injection, handling, and associated periods of very brief separation from the dam, which influence endocrine responses in the pups (Walker et al. 1991, Salzmann et al. 2004). Catecholamine release from the sympathetic nervous system (SNS) may be 
a mediator of these responses (Young 2000). A previous study found that the transcription of the human leptin gene is activated by hypoxia, via the transcription factor hypoxia-inducible factor-1 (Ambrosini et al. 2002). This lends support to the present study, but it does not provide a complete explanation of our findings.

To our knowledge, the present study is the first to report the effects of dexamethasone on plasma leptin in the hypoxic neonate. Interestingly, concomitant hypoxia attenuated the stimulatory effect of dexamethasone on leptin. A previous study suggested that catecholamines directly inhibit leptin production by binding to adipocyte adrenergic receptors (Scriba et al. 2000). It is possible that increased SNS activity in the hypoxic pup blunted the leptin response to dexamethasone.

\section{Ghrelin}

Information regarding the role of ghrelin in the control of appetite and growth in the adult is currently expanding, although less is known of its role in development (Bellone et al. 2004, Small \& Bloom 2004). Ghrelin is most notably produced by endocrine cells of the gastric mucosa, but is also produced in the intestine, hypothalamus, and pancreas (Mozid et al. 2003, Wierup et al. 2004). We have previously shown that hypoxia does not affect total or active ghrelin in the plasma of neonatal rats, suggesting that the anorectic effect of hypoxia does not involve changes in ghrelin (Raff 2003). Ghrelin stimulates the HPA axis at the level of the hypothalamus, and glucocorticoids have been shown to be permissive for ghrelin-induced food intake and accumulation of fat mass (Tung et al. 2004). A study in humans found that endogenous and exogenous glucocorticoids decrease plasma ghrelin (Otto et al. 2004). The present results, to our knowledge, are the first to describe glucocorticoid-induced increases in ghrelin. This may be an important process in the developing animal. Dexamethasone-induced increases in plasma ghrelin in hypoxic neonates could be a mechanism by which appetite is stimulated to overcome the direct anorectic effects of hypoxia (Kayser 1992). We also speculate that the attenuation by hypoxia of dexamethasone-induced increases in leptin favors this orexigenic effect. These findings may be important in understanding the control of neonatal growth in health and disease.

\section{ACTH/corticosterone}

We have previously shown that hypoxia from birth to 7 days of age increases plasma corticosterone without affecting plasma ACTH (Raff et al. 2003). The present study confirmed these findings and also showed that pituitary POMC and CRHR1 mRNA expression are unaffected by hypoxia. The mediator of this sustained increase in corticosterone has yet to be elucidated, but our previous study indicated that it might be driven by increases in SNS activity (Raff et al. 2004).

Prior dexamethasone treatment (PD3-6) resulted in subsequent increases in plasma ACTH in 7-day-old pups with plasma corticosterone remaining low. It is likely that dexamethasone initially suppressed the HPA axis at the hypothalamus and pituitary, also decreasing adrenocortical function (Ford et al. 1997). After the discontinuation of dexamethasone, plasma corticosterone remained suppressed such that, in the absence of glucocorticoid negative feedback, the pituitary rapidly increased ACTH production in order to reverse the suppression of adrenocortical function. The tapering dexamethasone regimen used in the current study likely facilitated this quick restoration of ACTH release, a finding in the neonate not found in the adult (Nicholson et al. 1984).

This temporal sequence of the recovery of the HPA axis is also observed clinically, albeit in a longer time domain (Chrousos 2001). That is, dexamethasone suppresses plasma ACTH, which results in a decrease in adrenocortical function. When exogenous corticosteroids are discontinued, ACTH recovers first and overshoots, which is necessary to reverse the decrease in adrenocortical function. The main difference between our results and this well-known clinical phenomenon is the time-course of the recovery in that the increase in ACTH in the neonate occurred within $24 \mathrm{~h}$ of the last (and lowest) dexamethasone dose. It is likely that the short duration and tapering regimen of glucocorticoid therapy in the current study allowed the rapid recovery of ACTH secretion. We suspect that adrenocortical function, which normally lags behind ACTH, would have soon followed. Although this study was not designed to optimize dexamethasone dosing in the neonate, it appears that this regimen, which was designed to mimic dexamethasone therapy in human neonates (Flagel et al. 2002), allows a very rapid recovery of pituitary function.

Since pituitary POMC mRNA expression remained suppressed after the cessation of dexamethasone treatment, the increased ACTH secretion was likely the result of increased post-translational processing possibly driven by increased corticotropin-releasing hormone $(\mathrm{CRH})$ during recovery from dexamethasone-induced inhibition (Lim et al. 2002). Previous studies have shown that dexamethasone treatment increases CRHR 1 mRNA expression in the adult rat pituitary (Rabadan-Diehl et al. 1997). The present study measured increased CRHR 1 expression in normoxic and hypoxic 7-day-old rat pituitaries, $24 \mathrm{~h}$ after the final dose of a tapering regimen of dexamethasone. Increased CRHR1 expression may be $\mathrm{CRH}$-driven and/or the result of an intracellular feedback mechanism in the pituitary (i.e. increased CRHR1 expression to overcome dexamethasone-induced suppression of POMC mRNA). Our findings illustrate that, following suppression with dexamethasone, the neonatal HPA axis regains 
responsiveness more quickly than that of the adult (Nicholson et al. 1984), and that this may occur predominantly at the pituitary level (Ford et al. 1997).

\section{Summary}

The present study demonstrated that a tapering dose regimen of dexamethasone in the neonatal rat modulates hormones involved in appetite and energy balance. Of great interest is the attenuation of the leptin response to dexamethasone in hypoxic pups. This may be a beneficial mechanism by which the developing animal attempts to maintain appetite in the face of the anorectic effect of hypoxia (Kayser 1992). Dexamethasone-induced ghrelin production, which was not inhibited by hypoxia, may produce a similar effect. The insulin-resistant state produced by hypoxia (Bruder et al. 2004) serves to divert energy substrates away from peripheral tissues (i.e. adipose and muscle). Dexamethasone therapy is likely to augment this effect. This would allow critical tissues such as the brain to preserve function during the hypoxic insult, and would also explain growth failure (Bruder et al. 2004). Hypoxia-induced increases in corticosterone (Raff et al. 1999b) are also likely to contribute to the insulin resistance and possibly play a role in maintaining appetite.

These findings have implications in short-term metabolic and endocrine control in the neonate. We also speculate that there may be long-term consequences of these short-term adaptations (Bruder et al. 2004). Increases in leptin during development may permanently alter the neural mechanisms controlling food intake and energy balance (Bouret et al. 2004, Pinto et al. 2004). Likewise, neonatal hyperinsulinemia is also suspected of causing metabolic disturbances in the adult (e.g. insulin resistance and obesity) (Dorner \& Plagemann 1994, Petry et al. 2001). Growth failure, and associated periods of catch-up growth, may also lead to subsequent metabolic disease (De Souza \& Moura 2000, Hales \& Ozanne 2003). Increased concentrations of endogenous or exogenous glucocorticoids in the neonate have also been implicated in subsequent HPA axis dysfunction (Flagel et al. 2002), and may be detrimental to brain development (Lindahl et al. 1988, Yeh et al. 2004). Neonatal hypoxia also leads to long-term changes in sympathoadrenal function (Soulier et al. 1997). Therefore, it is important not only to understand the acute responses to neonatal hypoxia and dexamethasone treatment, but also to relate these responses to long-term maintenance of health.

\section{Acknowledgements}

The authors would like to thank Barbara Jankowski, Peter Homar, and Rebecca Kittell for their expert technical assistance. They would also like to thank Dr Martin Oaks and Karen Hallett for the production of the CRHR1 clone. This study was supported by NIH Grants DK54685 (H R) and DK62442 (L J) and St Luke's Medical Center (Aurora Health Care). The authors declare that there is no conflict of interest that would prejudice the impartiality of this scientific work.

\section{References}

Ambrosini G, Nath AK, Sierra-Honigmann MR \& Flores-Riveros J 2002 Transcriptional activation of the human leptin gene in response to hypoxia - involvement of hypoxia-inducible factor 1 . Journal of Biological Chemistry 277 34601-34609.

American Academy of Pediatrics \& Canadian Paediatric Society 2002 Postnatal corticosteroids to treat or prevent chronic lung disease in preterm infants. Pediatrics 109 330-338.

Bellone S, Castellino N, Broglio F, Rapa A, Vivenza D, Radetti G, Bellone J, Gottero C, Ghigo E \& Bona G 2004 Ghrelin secretion in childhood is refractory to the inhibitory effect of feeding. Journal of Clinical Endocrinology and Metabolism 89 1662-1665.

Bouret SG, Draper SJ \& Simerly RB 2004 Trophic action of leptin on hypothalamic neurons that regulate feeding. Science 304 108-110.

Bruder ED, Lee PC \& Raff H 2004 Metabolic consequences of hypoxia from birth and dexamethasone treatment in the neonatal rat: comprehensive hepatic lipid and fatty acid profiling. Endocrinology 145 5364-5372.

Bruder ED, Lee PC \& Raff H 2005 Dexamethasone treatment in the newborn rat: fatty acid profiling of lung, brain, and serum lipids. Journal of Applied Physiology 98 981-990.

Chrousos GP 2001 Glucocorticoid therapy. In Endocrinology and Metabolism, edn 4, pp 609-632. Eds P Felig \& LA Frohman. New York: McGraw-Hill, Inc. Medical Publishing Division.

Dallman MF 2003 Fast glucocorticoid feedback favors 'the munchies'. Trends in Endocrinology and Metabolism 14 394-396.

De Souza CFJ \& Moura AS 2000 Undernutrition during early lactation period induces metabolic imprinting leading to glucose homeostasis alteration in aged rats. Research Communications in Molecular Pathology and Pharmacology 108 213-226.

Dorner G \& Plagemann A 1994 Perinatal hyperinsulinism as possible predisposing factor for diabetes mellitus, obesity and enhanced cardiovascular risk in later life. Hormone and Metabolic Research 26 213-221.

Flagel SB, Vazquez DM, Watson SJ \& Neal CR 2002 Effects of tapering neonatal dexamethasone on rat growth, neurodevelopment, and stress response. American Journal of Physiology-Regulatory, Integrative and Comparative Physiology 282 R55-R63.

Ford LR, Willi SM, Hollis BW \& Wright NM 1997 Suppression and recovery of the neonatal hypothalamic-pituitary-adrenal axis after prolonged dexamethasone therapy. Journal of Pediatrics 131 722-726.

Frankel L \& Stevenson DK 1987 Metabolic emergencies of the newborn: hypoxemia and hypoglycemia. Comprehensive Therapy 13 $14-19$.

Friedman AH \& Fahey JT 1993 The transition from fetal to neonatal circulation: normal responses and implications for infants with heart disease. Seminars in Perinatology 17 106-121.

Grongnet JF 1984 Metabolic consequences of induced hypoxia in newborn lambs. Annales de Recherches Veterinaires 15 17-28.

Hales CN \& Ozanne SE 2003 For debate: Fetal and early postnatal growth restriction lead to diabetes, the metabolic syndrome and renal failure. Diabetologia 46 1013-1019.

He J, Varma A, Weissfeld LA \& Devaskar SU 2004 Postnatal glucocorticoid exposure alters the adult phenotype. American Journal of Physiology - Regulatory, Integrative and Comparative Physiology 287 R198-R208.

Ishida-Takahashi R, Uotani S, Abe T, Degawa-Yamauchi M, Fukushima T, Fujita N, Sakamaki H, Yamasaki H, Yamaguchi Y 
\& Eguchi K 2004 Rapid inhibition of leptin signaling by glucocorticoids in vitro and in vivo. Journal of Biological Chemistry 279 19658-19664.

Jacobson L 2000 CRH and NPY are not decreased in hypophagic, protein-deprived rats. Peptides 21 1487-1493.

Jacobson L, Zurakowski D \& Majzoub JA 1997 Protein malnutrition increases plasma ACTH and anterior pituitary proopiomelanocortin messenger ribonucleic acid in the rat. Endocrinology 138 1048-1057.

Kayser B 1992 Nutrition and high altitude exposure. International Journal of Sports Medicine 13 S129-S132.

Lee PC, Struve M, Lewis SM \& Raff H 2002 Neonatal hypoxia in the rat: effects on exocrine pancreatic development. Journal of Pediatric Gastroenterology and Nutrition 34 542-547.

Lee PC, Struve M \& Raff H 2003 Effects of hypoxia on the development of intestinal enzymes in neonatal and juvenile rats. Experimental Biology and Medicine 228 717-723.

Lewandowski K, Randeva HS, O'Callaghan CJ, Horn R, Medley GF, Hillhouse EW, Brabant G \& O'Hare P 2001 Effects of insulin and glucocorticoids on the leptin system are mediated through free leptin. Clinical Endocrinology 54 533-539.

Lim MC, Shipston MJ \& Antoni FA 2002 Posttranslational modulation of glucocorticoid feedback inhibition at the pituitary level. Endocrinology 143 3796-3801.

Lindahl E, Michelsson K, Helenius M \& Parre M 1988 Neonatal risk factors and later neurodevelopmental disturbances. Developmental Medicine and Child Neurology 30 571-589.

Meier U \& Gressner AM 2004 Endocrine regulation of energy metabolism: review of pathobiochemical and clinical chemical aspects of leptin, ghrelin, adiponectin, and resistin. Clinical Chemistry 50 1511-1525.

Mozid AM, Tringali G, Forsling ML, Hendricks MS, Ajodha S, Edwards R, Navarra P, Grossman AB \& Korbonits M 2003 Ghrelin is released from rat hypothalamic explants and stimulates corticotrophin-releasing hormone and arginine-vasopressin. Hormone and Metabolic Research 35 455-459.

Neary NM, Goldstone AP \& Bloom SR 2004 Appetite regulation: from the gut to the hypothalamus. Clinical Endocrinology $\mathbf{6 0}$ 153-160.

Ng PC, Lam CWK, Lee CH, Fok TF, Chan HIS, Ma KC \& Wong E 2002 Changes in serum leptin concentration after corticosteroid treatment in preterm infants. Acta Paediatrica 91 684-690.

Nicholson S, Campbell E, Torrellas A, Beckford U, Altaher R, Sandford R, Scraggs R, Gillham B \& Jones M 1984 Recovery of the hypothalamo-pituitary-adrenocortical axis in the rat after long-term dexamethasone treatment. Neuroendocrinology 39 343-349.

Otto B, Tschop M, Heldwein W, Pfeiffer AF \& Diederich S 2004 Endogenous and exogenous glucocorticoids decrease plasma ghrelin in humans. European Journal of Endocrinology 151 113-117.

Perrin MH, Donaldson CJ, Chen R, Lewis KA \& Vale WW 1993 Cloning and functional expression of a rat brain corticotropin releasing factor (CRF) receptor. Endocrinology 133 3058-3061.

Petry CJ, Ozanne SE \& Hales CN 2001 Programming of intermediary metabolism. Molecular and Cellular Endocrinology 185 81-91.

Pinto S, Roseberry AG, Liu H, Diano S, Shanabrough M, Cai X, Friedman JM \& Horvath TL 2004 Rapid rewiring of arcuate nucleus feeding circuits by leptin. Science 304 110-115.

Pozzoli G, Bilezikjian LM, Perrin MH, Blount AL \& Vale WW Corticotropin-releasing factor (CRF) and glucocorticoids modulate the expression of type I CRF receptor messenger ribonucleic acid in rat anterior pituitary cell cultures. Endocrinology 137 65-71.

Rabadan-Diehl C, Makara G, Kiss A, Zelena D \& Aguilera G 1997 Regulation of pituitary corticotropin releasing hormone (CRH) receptor $\mathrm{mRNA}$ and $\mathrm{CRH}$ binding during adrenalectomy: role of glucocorticoids and hypothalamic factors. Journal of Neuroendocrinology 9 689-697.

Raff H 2003 Total and active ghrelin in developing rats during hypoxia. Endocrine 21 159-161.
Raff H 2004 Neonatal dexamethasone therapy: short- and long-term consequences. Trends in Endocrinology and Metabolism 15 351-352.

Raff H \& Chadwick CJ 1986 Aldosterone responses to ACTH during hypoxia in conscious rats. Clinical and Experimental Pharmacology and Physiology 13 827-830.

Raff H, Sandri RB \& Segerson TP 1986 Renin, ACTH, and adrenocortical function during hypoxia and hemorrhage in conscious rats. American Journal of Physiology - Regulatory, Integrative and Comparative Physiology 250 R240-R244.

Raff H, Bruder ED \& Jankowski BM 1999a The effect of hypoxia on plasma leptin and insulin in newborn and juvenile rats. Endocrine $\mathbf{1 1}$ 37-39.

Raff H, Jankowski BM, Bruder ED, Engeland WC \& Oaks MK $1999 b$ The effect of hypoxia from birth on the regulation of aldosterone in the 7-day-old rat: plasma hormones, steroidogenesis in vitro, and steroidogenic enzyme messenger ribonucleic acid. Endocrinology 140 3147-3153.

Raff H, Bruder ED, Jankowski BJ \& Colman RJ 2001a Effect of neonatal hypoxia on leptin, insulin, growth hormone and body composition in the rat. Hormone and Metabolic Research 33 151-155.

Raff H, Bruder ED, Jankowski BM, Oaks MK \& Colman RJ $2001 b$ Growth hormone therapy during neonatal hypoxia in rats: body composition, bone mineral density, and insulin-like growth factor-1 expression. Endocrine 16 139-143.

Raff H, Jacobson L \& Cullinan WE 2003 Eleveated corticosterone and inhibition of ACTH responses to CRH and ether in the neonatal rat: effect of hypoxia from birth. American Journal of Physiology - Regulatory, Integrative and Comparative Physiology 285 R1224-R1230.

Raff H, Lee JJ, Widmaier EP, Oaks MK \& Engeland WC 2004 Basal and adrenocorticotropin-stimulated corticosterone in the neonatal rat exposed to hypoxia from birth: modulation by chemical sympathectomy. Endocrinology 145 79-86.

Routh VH, Hamilton JS, Stern JS \& Horwitz BA 1993 Litter size, adrenalectomy and high fat diet alter hypothalamic monoamines in genetically lean $(\mathrm{Fa} / \mathrm{Fa})$ Zucker rats. Journal of Nutrition 123 74-84.

Salzmann C, Otis M, Long H, Roberge C, Gallo-Payet N \& Walker CD 2004 Inhibition of steroidogenic response to adrenocorticotropin by leptin: implications for the adrenal response to maternal separation in neonatal rats. Endocrinology 145 1810-1822.

Scriba D, Aprath-Husmann I, Blum WF \& Hauner H 2000 Catecholamines suppress leptin release from in vitro differentiated subcutaneous human adipocytes in primary culture via beta1- and beta2-adrenergic receptors. European Journal of Endocrinology 143 439-445.

Sinkin RA, Dweck HS, Horgan MJ, Gallaher KJ, Cox C, Maniscalco WM, Chess PR, D’Angio CT, Guillet R, Kendig JW et al. 2000 Early dexamethasone - attempting to prevent chronic lung disease. Pediatrics 105 542-548.

Small CJ \& Bloom SR 2004 Gut hormones and the control of appetite. Trends in Endocrinology and Metabolism 15 259-263.

Soriano-Guillen L, Barrios V, Chowen JA, Sanchez I, Vila S, Quero J \& Argente J 2004 Ghrelin levels from fetal life through early adulthood: relationship with endocrine and metabolic and anthropometric measures. Journal of Pediatrics 144 30-35.

Soulier V, Peyronnet J, Pequignot JM, Cottet-Emard JM, Lagercrantz H \& Dalmaz Y 1997 Long-term impairment in the neurochemical activity of the sympathoadrenal system after neonatal hypoxia in the rat. Pediatric Research 42 30-38.

Spinedi E \& Gaillard RC 1998 A regulatory loop between the hypothalamo-pituitary-adrenal (HPA) axis and circulating leptin: a physiological role of ACTH. Endocrinology 139 4016-4020.

Thomas T \& Marshall JM 1995 A study on rats of the effects of chronic hypoxia from birth on respiratory and cardiovascular responses evoked by acute hypoxia. Journal of Physiology 487 $513-525$. 
Tung YL, Hewson AK \& Dickson SL 2004 Glucocorticoid-dependent stimulation of adiposity and appetite by a ghrelin mimetic in the rat. European Journal of Endocrinology 150 905-911.

Walker CD, Scribner KA, Cascio CS \& Dallman MF 1991 The pituitary-adrenocortical system of neonatal rats is responsive to stress throughout development in a time-dependent and stressor-specific fashion. Endocrinology 128 1385-1395.

Wierup N, Yang S, McEvilly RJ, Mulder H \& Sundler F 2004 Ghrelin is expressed in a novel endocrine cell type in developing rat islets and inhibits insulin secretion from INS-1 (832/13) cells. Journal of Histochemistry and Cytochemistry 52 301-310.

Yeh TF, Lin YJ, Lin HC, Huang CC, Hsieh WS, Lin CH \& Tsai CH 2004 Outcomes at school age after postnatal dexamethasone therapy for lung disease of prematurity. New England Journal of Medicine 350 1304-1313.

Young JB 2000 Effects of neonatal handling on sympathoadrenal activity and body composition in adult male rats. American Journal of
Physiology - Regulatory, Integrative and Comparative Physiology 279 R1745-R1752.

Young JB 2002 Effects of litter size on sympathetic activity in young adult rats. American Journal of Physiology - Regulatory, Integrative and Comparative Physiology 282 R1113-R1121.

Zayour D, Azar ST, Azar N, Nasser M, Obeid M, Mroueh S, Dbaibo GS \& Bitar FF 2003 Endocrine changes in a rat model of chronic hypoxia mimicking cyanotic heart disease. Endocrine Research 29 191-200.

Received in final form 10 March 2005

Accepted 18 March 2005

Made available online as an

Accepted Preprint 21 March 2005 